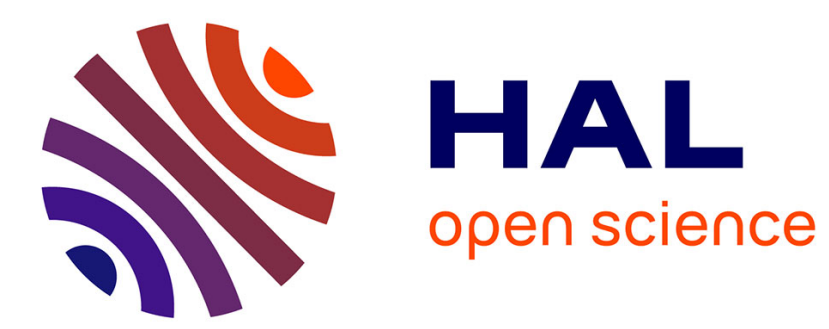

\title{
Gender accommodation in online cancer support groups Clive Seale
}

\section{To cite this version:}

Clive Seale. Gender accommodation in online cancer support groups. Health:, 2006, 10 (3), pp.345360. 10.1177/1363459306064495 . hal-00571424

\section{HAL Id: hal-00571424 https://hal.science/hal-00571424}

Submitted on 1 Mar 2011

HAL is a multi-disciplinary open access archive for the deposit and dissemination of scientific research documents, whether they are published or not. The documents may come from teaching and research institutions in France or abroad, or from public or private research centers.
L'archive ouverte pluridisciplinaire HAL, est destinée au dépôt et à la diffusion de documents scientifiques de niveau recherche, publiés ou non, émanant des établissements d'enseignement et de recherche français ou étrangers, des laboratoires publics ou privés. 


\title{
Gender accommodation in online cancer support groups
} 1363-4593; Vol 10(3): 345-360

\author{
Clive Seale \\ Brunel University, $U K$
}

\begin{abstract}
The postings made to Internet forums by relatives and friends of people with breast and prostate cancer are described. Women post very frequently on the prostate cancer forum and assume a communication style that is similar to women elsewhere, prioritizing emotional forms of communication over the informational forms preferred by men and showing only mild signs of accommodation to a male style. Men on the breast cancer forum are in a minority and are often responding to the current or anticipated loss of a partner. Their communication behaviour is radically different from that required by dominant conceptions of masculinity. They prioritize emotional communication and the emotional welfare of family members. They experience this new form of communication as unsettling to their conceptions of traditional masculinity. Internet cancer support groups thus favour a form and content of communication generally associated with women's culture.
\end{abstract}

KEYWORDS cancer; communication; comparative keyword analysis; gender; Internet; support group

ADdress Clive Seale, Professor of Sociology, School of Social Sciences and Law, Brunel University, Uxbridge, Middlesex, UB8 3PH, UK. [E-mail: clive.seale@brunel.ac.uk]

Gender differences in the personal experience of cancer have been detected in numerous psychosocial studies (Harrison et al., 1995; Krizek et al., 1999; Kiss and Meryn, 2001) as well as in media and Internet representations (Seale, 2002, 2005a, 2005b). Broadly speaking, social, cultural and psychological research shows that men are expected to deal with cancer on their own, or with their doctors, or sometimes with (usually female) partners. Male behavioural norms emphasize decisiveness and emotional control, a position of power being reached through the acquisition of (largely medical) information. Women, on the other hand, experience (and are expected to experience) cancer as a disruption to their emotional lives, social and family networks, and expect to work actively on all these 
dimensions of their lives when dealing with the illness, for example more often joining support groups for this purpose.

At the same time, behaviour that deviates from such norms has been described. Pitts (2004), for example, in a study of personal pages of women with breast cancer notes that these 'offer potentially critical opportunities for women's knowledge-making in relation to what are often highly political aspects of the body, gender and illness'. She warns, though, that 'the Internet is not an inherently empowering technology, and ... can be a medium for affirming norms of femininity' (2004: 33). Gray et al. show how responses to prostate cancer can involve renegotiation of 'performances of masculinity' (2002: 43), by which they mean the kind of performance described in the opening paragraph of this article.

Gender difference in language use and illness behaviour in the 'offline' or 'real' world are well documented across many settings. Coates (2004), for example, in reviewing the field of gender differences in language use, describes studies documenting the way men frequently interrupt women in mixed-sex conversations, and the contest for dominance typically enacted in men-only talk. Women, on the other hand, commonly use language to enact co-operative interaction styles, do the 'interactional shitwork' (Fishman, 1977, 1979) of agreeing, encouraging and supporting others in mixed-sex groups, and in women-only friendship groups prefer mutual support and intimate self-disclosure. In health matters, gender differences in behaviour are often quite distinct. Women's involvement in monitoring and promoting family health is well known (Umberson, 1992); men's health behaviour includes a tendency to consult late and consult less, often relying on female partners to worry about their health or interpret symptoms and persuade them to seek help (O'Brien et al., 2005).

Researchers in the general field of gender studies have also become interested in fluid and contested notions of masculinity and femininity. Earlier essentialist conceptions have been replaced with a vision of the social construction of gender, so that performative aspects are increasingly stressed (Butler, 1990). A single individual may adjust their performance of the gendered aspects of identity for different audiences, or at different times stress different degrees of attachment to the maintenance of clear gender boundaries. Additionally, recent scholarship has demonstrated considerable interest in documenting behaviour that involves performances of masculinity or femininity that deviate from, or are subversive of hegemonic norms of the sort described in the opening paragraph of this article (Hearn and Morgan, 1990; Kimmel, 1994; Connell, 1995; Wetherell and Edley, 1999). A variant on this line of analysis is provided by conversation analysts interested in gender and language (for example, Stokoe and Weatherall, 2002; Speer, 2005). Following the injunction of Schegloff (1997), such research seeks to solve the problem of 'essentialist' readings by considering only those passages of speech where participants demonstrably make gender a topic of their talk. However, such work is controversial 
in its claim to reduce the dependency of the analyst on pre-existing knowledge of the gender of speakers or on other matters extraneous to the texts considered (Billig, 1999).

The initial focus of research on gender differences in Internet use was on barriers to access that, in the early days of the Internet, significantly disadvantaged women. With the achievement of gender parity in access (at least for users in more economically developed countries such as the USA), research interest has shifted to gender differences in what people do with and on the Internet. As Herring (2001) in her review of this field observes, at first many believed that gender might be less important in Internet communications than in face-to-face communication because of the lack of physical and auditory clues. Nevertheless, research studies across many Internet applications and sites have documented the enduring existence of gender differences in online environments. Much Internet research records forms of male dominance on the Internet, either in interactions on synchronous and asynchronous messaging systems, or in website representations. Instances of sexual harassment, of quantitative dominance of mixed-sex interaction and the intimidating effect of pornography have all been cited as indicating this dominance (Herring, 2001).

Studies of cancer support groups appear to provide powerful examples of behaviour that is highly linked to the kind of gendered norms of the sort identified earlier. In two studies describing respectively face-to-face groups (Gray et al., 1996) and Internet-based groups (Klemm et al., 1999), differences between men with prostate cancer and women with breast cancer have been described. Women's groups show a preference for friendship, mutual support and emotional disclosure, in Gray's study resisting the involvement of outsiders. Men's groups show a preference for giving and seeking (usually medical) information and, in face-to-face groups, organize meetings so that they are framed as educational opportunities, often involving talks from invited experts such as oncologists.

The present study examines aspects of gender in two popular online cancer support groups. An earlier article (Seale et al., 2006) compared men and women with cancer who take part in these forums, which cater for breast and prostate cancers. This confirmed the findings of the studies reviewed earlier, showing that women enacted emotional support and self-disclosure, whereas men were oriented to discovering medical information by, for example, exchanging medical website references with each other. Women used more 'superlatives' such as 'amazing', 'brilliant' and 'marvellous', indicating their more overtly emotional mode of address. Men's experience of disease was highly localized to dysfunctions of particular bodily regions, whereas women demonstrated a more holistic experience of illness.

The focus of the present article is on the quite significant number of people, usually relatives and friends of people with cancer, who participate in the forums of the 'opposite' sex (in other words, men on the breast cancer forum and women on the prostate cancer forum). This is done in order to 
explore the possibility that such individuals may be using the relative freedom of the Internet to enact forms of masculinity and femininity deviating from the stereotyped gendered norms described earlier, by entering an 'other' populated Internet forum. Linguistically, this might involve raising unconventional topics or using language in ways that break with gendered norms. It might also involve convergent 'communication accommodation', in which a communicator adopts the norms of a majority speech community in which he or she is a temporary visitor (Street and Giles, 1982; Giles and Wiemann, 1987; Giles et al., 1991). Baym (1996), for example, found that men in a female-dominated computer-mediated discussion environment adopted less aggressive styles there than in maledominated groups.

\section{Methods}

This article reports a comparative analysis of prostate and breast cancer experience, drawing on a complete retrieval (on 20 April 2005) of all current and archived postings to the online forums/message boards of the two most popular UK-based breast and prostate cancer websites (www.prostatecancer.org.uk and www.breastcancercare.org.uk). Forums and message boards provide online support, enabling individuals to post and respond to messages over time. Because these are open access public forums, postings were considered to be in the public domain for ethical purposes although prominently biographical details have been concealed in any quotations used in this report. Messages were converted into text files and grouped according to name of author. The content of messages was inspected to determine the gender of the author, whether the author was a person with cancer, a person investigating symptoms that they felt might be cancer, the relative or friend of a person with cancer or some other type of person. This article largely focuses on postings made by people who identified themselves as opposite-sex relatives and friends of people with cancer. The focus on them is achieved by comparing their postings with postings made by a variety of other groups of people on the forums.

Analysis employed Wordsmith software developed for corpus linguistics studies (Scott, 1996, 1997; Adolphs et al., 2004) to compare the relative 'keyness' of keywords. In conventional corpus linguistics, the text of interest is compared with a larger reference corpus (for example, the British National Corpus) to elucidate stylistic, grammatical or other characteristics. 'Keywords' are words that occur with particular frequency when compared with the reference corpus. These words are often important indicators of both the mode of expression and the content of the text thus studied.

In this analysis, comparative keyword analysis was done without use of such a general reference corpus. Seale et al. (2006) provide further details and a validation of this method, which will be new to many qualitative social researchers. The method differs significantly from methods of qualitative 
thematic analysis conventionally applied by social researchers to material such as interviews or Web forum postings (for example, Klemm et al., 1999). There are two main advantages to the method. The major themes that characterize very large amounts of text can be identified more economically than in conventional qualitative thematic analysis, and the method is more inductive than such conventional analysis. This is because 'keywords' are identified according to purely mechanical criteria, confronting the analyst with evidence that a conventional reading might suppress from view. It is, nevertheless, a method that enables an interpretive approach, since its essential purpose is to identify meaningful constellations of words that 'make sense' in terms of an emerging analytic theme. Disadvantages include difficulties in examining interactional patterns between speakers or writers, and (for comparative keyword analysis) an exclusive focus on differences between texts rather than similarities.

Comparative keyword analysis involves the direct comparison of relevant texts with each other, rather than with some neutral reference corpus, and then using the quantitative output from this to facilitate an interpretive, qualitative analysis focusing on the meanings of word clusters associated with keywords. For example, such an analysis might indicate that women use the word 'fear' 100 times within a collection of 1000 words that they have produced (e.g. 10\%) and men use it 100 times in a collection of 10,000 words that they have produced (e.g. 1\%). This would indicate that the word is more 'key' in the women's text than in the men's text.

For this analysis, text produced by relatives and friends of people with prostate cancer was directly compared with that produced by relatives and friends of people with breast cancer. Other comparisons were done to elucidate the themes characteristic of the two groups of concern in this article and are described in the results section. Additionally, keywords in their contexts (KWIC lists) were examined, and Wordsmith was also used where necessary to examine phrases most frequently associated with keywords. Keywords were then classified into meaningful categories (shared semantic fields) in a process analogous to the development of a coding scheme for the interpretive qualitative analysis of text. Thus keywords that were found to relate to 'feelings' were identified, or to 'research', or to 'body parts'. A fuller account of this categorization (or 'coding scheme' as it might be called in a conventional qualitative thematic analysis) is given in Seale et al. (2006).

This enabled important and meaningful comparative aspects of these large bodies of text to be identified. This could be done in a more economical and potentially replicable manner than conventional qualitative thematic analysis. At the same time, the inductive approach to formulating coding categories allows for a greater openness to new findings than is allowed by some text analysis software programs (for example, Pennebaker et al., 2001) that rely on pre-formulated dictionaries to allocate words to pre-specified categories. 
health: $10(3)$

\section{Results}

\section{Quantitative comparison}

Table 1 shows that the breast cancer forum is considerably larger than the prostate cancer forum. Relatives and friends participate in both forums but, on the breast cancer forum, people with cancer are in a majority, whereas in the prostate forum they participate in roughly equal numbers. This is largely because of the high level of participation by female relatives and friends on the prostate cancer forum, who post somewhat more messages and longer messages than the men on this forum. Male relatives and friends are rather inactive on both forums although male relatives and friends post particularly long messages on the breast forum. Notably, women show overall quantitative dominance on both forums if measured in numbers of

Table 1 People and postings on breast and prostate cancer internet forums

\begin{tabular}{|c|c|c|c|c|c|c|}
\hline & People & Posts & $\begin{array}{l}\text { Mean posts } \\
\text { (min-max) } \\
\text { per person }\end{array}$ & $\begin{array}{l}\text { Total } \\
\text { words }\end{array}$ & $\begin{array}{l}\text { Mean } \\
\text { words per } \\
\text { person }\end{array}$ & $\begin{array}{l}\text { Mean } \\
\text { words per } \\
\text { post }\end{array}$ \\
\hline \multicolumn{7}{|c|}{ A. Breast cancer forum } \\
\hline \multicolumn{7}{|c|}{ People with cancer } \\
\hline Female & 900 & 10,884 & $12.1(1-514)$ & $1,361,911$ & 1,513 & 125.1 \\
\hline Male & 4 & 39 & $9.8(1-24)$ & 6,546 & 1,637 & 167.8 \\
\hline \multicolumn{7}{|c|}{ Relatives and friends } \\
\hline Female & 109 & 410 & $3.8(1-52)$ & 59,349 & 544 & 144.8 \\
\hline Male & 55 & 186 & $3.4(1-18)$ & 31,748 & 577 & 170.7 \\
\hline Others & 112 & 281 & $2.5(1-20)$ & 32,734 & 292 & 116.5 \\
\hline Total & 1,180 & 11,800 & $10.0(1-514)$ & $1,492,288$ & 1,265 & 126.5 \\
\hline \multicolumn{7}{|c|}{ B. Prostate cancer forum } \\
\hline \multicolumn{7}{|c|}{ People with cancer } \\
\hline Male & 153 & 1,873 & $12.2(1-188)$ & 267,459 & 1,748 & 142.8 \\
\hline \multicolumn{7}{|c|}{ Relatives and friends } \\
\hline Female & 138 & 2,189 & $15.9(1-427)$ & 365,511 & 2,649 & 167.0 \\
\hline Male & 14 & 47 & $3.4(1-17)$ & 5,275 & 377 & 112.2 \\
\hline Others & 49 & 116 & $2.4(1-13)$ & 14,804 & 302 & 127.6 \\
\hline Total & 354 & 4,225 & $11.9(1-427)$ & 653,049 & 1,845 & 154.6 \\
\hline \multicolumn{7}{|c|}{ C. Both forums } \\
\hline \multicolumn{7}{|c|}{ People with cancer } \\
\hline Female & 900 & 10,884 & $12.1(1-514)$ & $1,361,911$ & 1,513 & 125.1 \\
\hline Male & 157 & 1,912 & $12.2(1-188)$ & 274,005 & 1,745 & 143.3 \\
\hline All & 1,057 & 12,796 & $12.1(1-514)$ & $1,635,916$ & 1,548 & 127.8 \\
\hline \multicolumn{7}{|c|}{ Relatives and friends } \\
\hline Female & 247 & 2,599 & $10.5(1-427)$ & 424,860 & 1,720 & 163.5 \\
\hline Male & 69 & 233 & $3.4(1-18)$ & 37,023 & 537 & 158.9 \\
\hline All & 316 & 2,832 & $9.0(1-426)$ & 461,883 & 1,462 & 163.1 \\
\hline All females & 1,226 & 13,722 & $11.2(1-514)$ & $1,814,576$ & 1,480 & 132.2 \\
\hline All males & 242 & 2,180 & $9.0(1-188)$ & 315,742 & 1,305 & 144.8 \\
\hline All people & 1,534 & 16,025 & $10.4(1-514)$ & $2,145,337$ & 1,399 & 133.9 \\
\hline
\end{tabular}


words posted. Overall, combining the two forums, where gender could be identified, women constituted 80 per cent of participants, posted 86 per cent of the messages and wrote 85 per cent of the words.

Much research on gender and language has been devoted to dispelling the myth that women talk more than men, and Coates (2004) reviews studies across many mixed-sex settings that show that in purely quantitative terms, men dominate talk. Spender's (1979) claim that women in such situations are normally allowed no more than 30 per cent of talking time appears to have been confirmed again and again in studies as diverse as school staff meetings and classroom interaction, other work settings, academic seminars, TV discussions and commercials, mock jury deliberations and experimental situations. Herring et al. $(1995,1998)$ have confirmed this quantitative dominance in studies of asynchronous Internet discussion lists among academics. In light of this, the quantitative parity and, in terms of the number of words posted, the quantitative dominance of women on the prostate cancer forum is surprising.

\section{Women relatives and friends on the prostate cancer forum}

Comparative keyword analysis reveals that the content and style of postings by women on this forum differ from men with prostate cancer along traditional gendered lines (Table 2). The differences are in fact very similar to the differences found when women with breast cancer are compared with men with prostate cancer (Seale et al., 2006). Table 2 shows that women on the prostate forum provide warmer greetings and support and discuss a wider range of feelings than do the men with prostate cancer on the forum. Their use of superlatives indicates a more overtly emotional mode of address. These superlatives are the contemporary equivalents of Lakoff's (1975) 'empty adjectives' (such as 'divine' and 'charming'), which she identified as typical of women's language. The range of words referring to people is far greater in women's postings, including references to family, children and siblings as well as self and the person with cancer. Male keywords reflect their greater concerns with staying in charge of decision making with the aid of research-based medical knowledge. Their sole 'feelings' keyword is quite revealing. A KWIC analysis reveals that 46 of the 74 instances of this were contained in the phrase 'demand a cure' (for prostate cancer).

Other kinds of keyword comparison, though, show that the women on this forum differ in some respects from women elsewhere. In part this is because of the mundane fact that women stand in different relation to prostate and breast cancer as a disease. Thus keyword comparison of female relatives and friends on the two forums showed that such women on the breast cancer forum had particular concerns about their potential to inherit the disease that were, for obvious reasons, not evident among women on the prostate cancer forum. This was indicated by the occurrence of keywords like 'genetic', 'carrier', 'history' and 'grandmother' in the postings on the breast cancer forum. 
health: 10(3)

Table 2 Keywords in text taken from the prostate cancer forum, comparing men with prostate cancer with women relatives and friends

\section{Greetings and support}

Men with prostate cancer (PC forum)

[All the] best, regards

\section{Feelings}

Men with prostate cancer ( $P C$ forum)

Demand

\section{Persons}

Men with prostate cancer (PC forum)

I, my, me, patients, wife, men, mine, patient

\section{Superlatives}

Men with prostate cancer (PC forum)

\section{Research}

Men with prostate cancer (PC forum)

Study, data, science, scientific, cases, studies

\section{Knowledge and communication}

Men with prostate cancer (PC forum)

Risk, choice, decision, comments, opted, comment, chose, question
Women relatives and friends ( $P C$ forum)

Love, $\mathrm{x}$, care, $\mathrm{xxx}$, dear, fondly, $\mathrm{xx}$, luv, lots [of love], hugs, [fingers] crossed, thank, sorry, $\mathrm{xxxx}$

Women relatives and friends (PC forum)

Glad, feels, awful, hard, sad, loved, hope, feel, feelings

Women relatives and friends (PC forum)

$\mathrm{He}$, his, we, dad, him, husband, he's, mum, you, our, us, you're, we're, I'm, hubby, dad's, we'll, everyone, her, husband's, he'll, he'd, dads, daughter, we've, children, family, husband, you've, himself, you'll, she, fellas, brother, sis, he's, we'd

Women relatives and friends (PC forum) Lovely, wonderful, terrible, nice, huge, dreadful, definitely

Women relatives and friends (PC forum)

Women relatives and friends (PC forum)

Know, think, thinking

Other findings indicated that women on the prostate forum may have accommodated somewhat to male concerns and interests. Thus, when compared with similar women on the breast cancer forum, the keywords of women relatives and friends on the prostate forum contained no 'feelings' keywords, whereas on the breast forum these included 'depression', 'strong', scared', helpless', 'want', upset' and 'feel'. When compared with women with breast cancer, the finding was repeated, as women with breast cancer recorded the keywords 'feel', 'felt', 'scared', 'awake [at night]' whereas women relatives and friends on the prostate forum recorded no feelings keywords. This suggests some degree of movement by women participating in the prostate forum towards the more emotionally restrained style of men, even though the results shown in Table 2 indicate that a substantial gender difference on this dimension remains. This difference may also be influenced by the fact that a proportion of women's postings on the prostate forum will have been in response to the concerns raised by men, which will have been less likely to contain emotional content.

Additionally, there is some evidence to suggest that women relatives and 
friends on the prostate forum serve a 'hostess' function in oiling the wheels of sociability on behalf of other interactants (Fishman's (1977) 'interactional shitwork') something that appears to be less necessary on the breast cancer forum. Thus, when compared with women with breast cancer, these women were significantly more likely to use 'thank', 'hello' and 'welcome'. Some typical phrases containing these words (chosen on the basis of their high frequency in KWIC displays) include:

welcome to this [board/forum/message board]

thank you for your [words/kind words/message/replies]

hello [all/everyone/again/(name of person)]

\section{Men on the breast cancer forum}

Unlike women on the breast cancer forum, these men demonstrate considerably greater difference from the dominant gendered norms described at the outset of this article. This appears to be largely due to a high proportion of male relatives and friends who were experiencing the need for emotional communication because of their feelings of loss, usually because of the recent or imminent death of their partners, though sometimes also because of the relationship difficulties they had experienced as a result of their partners' breast cancer. Such men experienced this switch into more emotional modes of communicating as unsettling, and, in some cases, threatening to familiar expectations of masculinity. Men with breast cancer experienced a related series of disruptions.

Inspection of the individual stories told by male relatives and friends on the breast forum revealed that of the 54 men where it was possible to tell from the content of their postings, most (48) were husbands or partners, the other 6 being sons of women with breast cancer. In eight cases the partner had died, and in a further eight the partner or mother was described as having secondaries or approaching death. Additionally, four men said that they were separating from their partners as a result of the strains created by the cancer experience.

Comparison of male relatives and friends on the breast forum with men with prostate cancer (Table 3 ) reveals differences that in some respects are parallel to the conventional gender differences shown in Table 2. These men on the breast forum use language in a way that is more like women than like men. In support of this conclusion, when a keyword comparison with women with breast cancer was done, very few significant keywords distinguishing the texts were produced, apart from those distinguishing self from other (e.g. 'I' and 'her'). Table 3 shows a wider range of feelings being discussed by men on the breast forum as well as a wider range of people, including children, friends and family, not just partners. The 'knowledge and communication' words of men with prostate cancer reflect interest in the assessment of risk and decision making, whereas the men on the breast forum appear more interested in interpersonal communication. Their 
Table 3 Keywords comparing male relatives and friends on breast cancer forum with males with cancer on prostate cancer forum

\author{
Greetings and support \\ Male relatives and friends ( $B C$ forum) $\quad$ Men with prostate cancer ( $P C$ forum) \\ Love, care, support, help Regards, hi, [good] luck \\ Feelings \\ Male relatives and friends ( $B C$ forum) \\ Want, wanted, feel, feels, wants, scared, lost, \\ strong, angry, upset, feelings, cope, emotional, \\ hard, feeling

\section{Persons} \\ Male relatives and friends ( $B C$ forum) \\ Her, she, mum, wife, we, partner, \\ ex [wife/partner], our, children, she's, kids, \\ relationship, I'm, daughter, people, person, \\ mother, family, partners, friends, I'm, you, \\ me, together, sister, both, yourself

\section{Knowledge and communication} \\ Male relatives and friends ( $B C$ forum) \\ Talk, think, chat, talking, know, telling \\ Selected other keywords \\ Male relatives and friends ( $B C$ forum) \\ Things, really, through, situation, deal, \\ Men with prostate cancer (PC forum) \\ Demand \\ happen \\ Men with prostate cancer (PC forum) \\ $\mathrm{He}$, men, cases, patients, I, dad \\ Men with prostate cancer (PC forum) \\ Risk, decision \\ Men with prostate cancer (PC forum)
}

'greetings and support' words focus more on emotional support, whereas the men with prostate cancer focus more on neutral or superficially cheerful greetings.

The 'selected other keywords' indicate some keywords distinguishing men on the breast forums that were otherwise not classified but are nevertheless helpful in characterizing the men's frame of mind. The word 'really' was most frequently associated with 'I really' and 'I'm really', suggesting a similar usage to the superlatives that characterize women's language and make it more emphatically emotional. This use of 'really' is similar to the use of 'so' for emphatic purposes claimed by Lakoff (1975) as a characteristic of women's speech (as in 'so charming'). The word 'through' was most frequently associated with the phrases 'going through', 'been through' or 'get through', indicating a self-perception as one who has had significantly disturbing experiences. 'Deal' was most commonly used in 'to deal with it', conveying a similar sense of having had considerable troubles. Thus these men were experiencing 'things', or a 'situation' in which much seemed to 'happen'.

Comparison of the keywords characterizing the feelings of women on the prostate forum with the keywords characterizing men on the breast forum is revealing. Tables 2 and 3 show that these were:

Women: glad, feels, awful, hard, sad, loved, hope, feel, feelings

Men: $\quad$ want, wanted, feel, feels, wants, scared, lost, strong, angry, upset, feelings, cope, emotional, hard, feeling 
Thus women's feeling keywords contain some that are notably positive (glad, loved, hope), whereas the only positive male keyword is 'strong'. It is clear, too, that these men often feel angry, as some extracts from KWIC lists for 'angry' indicate:

I'm getting angry with the lack of real answers

It does bother me \& makes me angry

I am very angry about this

This left me very angry

I'm angry about the way my Mum was treated

I'm upset, I'm ashamedly angry at her

A number of the men found their entry into a world of explicit communication about emotions was unsettling, or made them feel different. This was because, in some cases, they understood themselves to be deviating from what they believed to be the normal behaviour of men:

[I am] not the greatest person at talking about feelings so it may take a while to get going ... you try to be positive, but it is difficult to be like that all the time and can run out of positive statements, so all you do is give her a hug. Being male, I do not always know when they (hugs) are required of course ... and then feel guilty.

I suppose it is a fact that some men find it hard to get it across as well as they should! Me, after all we went through, it has left me with some sort of feeling of opening up more and just saying whatever I feel. This thing has some strange side effects on emotions that I don't think you can read or learn about other than experience them personally.

Others felt pleased and proud about how they had changed, or in how they felt different from other men because of their adoption of lifestyles or modes of communicating which they and their acquaintances normally associated with women:

Many people (mainly men) have said to me, 'I don't know how you do it' [adopted domestic roles, etc.]. There is no way I could or would have turned my back and fled from this situation ... Unfortunately many men will turn and run as showing emotion and compassion is mistaken as being weak in many eyes and some men's egos won't allow for this ... I hope this rambling helps you all and shows that there are men that care and do their best for their partners.

I gave up work to look after [our children] and am now a full-time carer. I found it very difficult to come to term with my wife's original diagnosis (about two and a half years ago). I concentrated purely on being practical (very male!) and denied not only my wife's emotional needs but mine too. Matters came to a bit of head and I had to seek counselling, which I think was the bravest thing I've ever done!!! ... I'm in touch with my feminine side which I think is important too! 
The experience of inhabiting a gender identity that seemed, to them, to deviate from conventional patterns made some feel empowered to advise others about the benefits of this, so that they became proselytizers on behalf of new or perhaps deviant forms of masculinity:

Your husband is not coping. It is, unfortunately, a very male response (though not all guys are like this, just to be clear) to 'shut down' and to not talk about things, and I'd agree this does not make things easier.

I would really recommend talking to someone (it's not that hard, guys!), a close friend or a professional and you will find your personal relationships will blossom. You have to open up, it may make you feel vulnerable and you may not even like where the process takes you, but you will be better for it at the end. Here endeth the sermon!!!!

It is important you accept your feelings and have some sort of outlet too! I know males are usually worse at dealing with the emotional side of things, but are there friends you can talk to very openly?

\section{Discussion}

The quantitative dominance of women in the breast cancer forum, and their parity, verging on quantitative dominance, in the prostate cancer forum suggests that, even though technically open to either gender, these illness support groups might reasonably be regarded as predominantly 'women's spaces'. That this appears to be true to a large degree of the prostate forum, which nominally caters for an illness that exclusively affects men, is quite striking. While one might have expected women on the prostate forum to be in a position of significant interactional disadvantage in terms of raising the issues of concern to them, it appears that by contrast they have considerable success in maintaining a focus on topics and styles of communication that are of concern to women involved in health matters generally.

The findings for women provide only mild evidence of accommodation to the communications of the opposite gender, in the sense that might be meant by communication accommodation theorists (Street and Giles, 1982; Giles and Wiemann, 1987; Giles et al., 1991) who across a range of intergroup communications have documented the phenomenon of one group modifying their speech and/or communication topics to suit the styles and interests of the other group. The major motivation cited by accommodation theorists for such behaviour is that of increasing rapport and feelings of affiliation and approval. Apart from the suggestion that women move slightly towards the more restrained emotional style of men in this setting, most of the evidence points to the relative immunity of women to such influence. Certainly, there is very little to suggest that these women are engaged in activities that deviate from the norms for female behaviour described at the start of this article. These women maintain their higher 
level of interest than men in communicating with and about feelings and about a wide variety of people affected by illness experience, and in this respect conform to dominant expectations of women identified in numerous research studies. Additionally, some evidence points to women on this forum performing the classic 'hostess' function of smoothing social interactions on behalf of other people, further indicating a generalized conformity to popular feminine stereotypes.

The men in the quantitative minority on the breast cancer forum, though, show behaviour that contrasts with the norms of traditional masculinity that emphasize emotional control and personal mastery. Clearly this is partly because of the personal circumstances that have driven many of them to participate in the forum. Communication accommodation theory, stressing the motivation of speakers to affiliate with co-present interactants, is somewhat inadequate in explaining what is happening here. The stories of many of these men indicate that the changes they are experiencing arise from their personal biographies as people experiencing the loss of their female partners, so that they seek opportunities for exploring emotions and experiences of caring responsibilities that are in some cases quite new to them. At the same time, they appear somewhat more concerned with the exploration of their own feelings than those of others. Thus their motives are not simply to provide here-and-now affiliation with the people they are communicating with, but reflect their own felt emotional needs as they face new circumstances in their lives. Oliffe (2005) describes a somewhat similar situation faced by men who experience impotence after prostatectomy; many such men adapt to this by redefining conventional masculine ideals of phallocentric sexuality.

The reflective comments of the men on the breast cancer forum suggest that their new selves often feel strange to them, that many of them feel relatively unskilled in this arena, so that if they become skilled then they must be (often uncomfortably) different from (perhaps imagined) other men. Some appear to respond to this by inhabiting their new self enthusiastically, and proselytizing about the value of stepping outside the traditional male role. Some appear to have feelings of anger about their difficult situations, or present a conflicting mixture of apologies about being present in women's space, and feelings of resentment about women's apparently easy possession of such space and the skills of emotional communication that go with it.

In light of this, it is instructive to re-visit the observation of Herring (2001) in reviewing studies of gender differences in mixed-sex online communication forums which show that these 'tend to disfavour women' (2001: 7), by which she means women who like to communicate according to predominant norms of femininity that emphasize communication of emotions and the sharing of personal experience. On these forums this appears not to be the case. Women on the prostate forum, perhaps because of their numerical almost-dominance, are able to communicate according to such norms 
without much sense of hindrance. Men on the breast cancer forum, on the other hand, participate largely on the basis that they adopt 'feminine' norms of communication, and clearly experience themselves to be engaged, sometimes rather inadequately, in a minority activity. These findings suggests some support for the view of Giddens (1992), who argues that women have nowadays pioneered the transformation of intimacy, largely through the appropriation of emotional skills so that women are "the emotional revolutionaries of modernity' while, on the whole, men experience a 'lapsed emotional narrative of self' (1992: 130).

\section{References}

Adolphs, S., Brown, B., Carter, R., Crawford, P. and Sahota, O. (2004). Applying corpus linguistics in a health care context. Journal of Applied Linguistics, 1(1), 9-28.

Baym, N. (1996). Agreements and disagreements in a computer-mediated discussion. Research on Language and Social Interaction, 29(4), 315-45.

Billig, M. (1999). Whose terms? Whose ordinariness? Rhetoric and ideology in conversation analysis. Discourse and Society, 10(4), 543-58.

Butler, J. (1990). Gender trouble: Feminism and the subversion of identity. New York: Routledge.

Coates, J. (2004). Women, men and language: A sociolinguistic account of gender differences in language. London: Pearson Education.

Connell, R.W. (1995). Masculinities. St Leonards, NSW: Allen \& Unwin.

Fishman, P.M. (1977). Interactional shitwork. Heresies, 2, 99-101.

Fishman, P.M. (1979). Interaction: The work women do. Social Problems, 24, 397-406.

Giddens, A. (1992). The transformation of intimacy: Sexuality, love and eroticism in modern societies. Cambridge: Polity Press.

Giles, H. and Wiemann, J.M. (1987). Language, social comparison and power. In C.R. Berger and S.H. Chaffee (Eds.), The handbook of communication science, pp. 350-84. Newbury Park, CA: Sage.

Giles, H., Coupland, J. and Coupland, N. (1991). Developments in applied sociolinguistics. Cambridge: Cambridge University Press.

Gray, R., Fitch, M., Davis, C. and Phillips, C. (1996). Breast cancer and prostate cancer self help groups: Reflections on differences. Psycho-oncology, 5, 137-42.

Gray, R.E., Fitch, M.I., Fergus, K.D., Mykhalovskiy, E. and Church, K. (2002). Hegemonic masculinity and the experience of prostate cancer: A narrative approach. Journal of Aging and Identity, 7(1), 43-62.

Harrison, J., Maguire, P. and Pitceathly, C. (1995). Confiding in crisis: Gender differences in pattern of confiding among cancer patients. Social Science and Medicine, 41(9), 1255-60.

Hearn, J. and Morgan, D. (1990). Men, masculinities and social theory: Critical studies on men and masculinities. London: Unwin Hyman.

Herring, S. (2001). Gender and power in online communication. Indiana: Indiana University, Center for Social Informatics Working Paper no. 01-05. Available at www.slis.indiana.edu/CSI/WP/WP01-05B.html

Herring, S., Johnson, D. and DiBenedetto, T. (1995). 'This discussion is going too far!': Male resistance to female participation on the Internet. In K. Hall and 
M. Bucholz (Eds.), Gender articulated: Language and the socially constructed self, pp. 67-96. New York: Routledge.

Herring, S.C., Johnson, D. and DiBenedetto, T. (1998). Participation in electronic discourse in a 'feminist' field. In J. Coates (Ed.), Language and gender: A reader, pp. 197-210. Oxford: Blackwell.

Kimmel, M. (1994). Masculinity as homophobia: Fear, shame and silence in the construction of gender identity. In H. Brod and M. Kaufman (Eds.), Theorizing masculinities, pp. 119-41. London: Sage.

Kiss, A. and Meryn, S. (2001). Effect of sex and gender on psychosocial aspects of prostate and breast cancer. British Medical Journal, 323, 1055-8.

Klemm, P., Hurst, M., Dearholt, S.L. and Trone, S.R. (1999). Gender differences on Internet cancer support groups. Computers in Nursing, 17(2), 65-72.

Krizek, C., Roberts, C., Ragan, R., Ferrara, J. and Lord, B. (1999). Gender and cancer support group participation. Cancer Practice, 7, 86-92.

Lakoff, R. (1975). Language and women's place. New York: Harper \& Row.

O'Brien, R., Hunt, K. and Hart, G. (2005). 'It's caveman stuff, but that is to a certain extent how guys still operate': Men's accounts of masculinity and help seeking. Social Science and Medicine, 61, 503-16.

Oliffe, J. (2005). Constructions of masculinity following prostatectomy-induced impotence. Social Science and Medicine, 60, 2249-59.

Pennebaker, J.W., Francis, M.E. and Booth, R.J. (2001). Linguistic inquiry and word count (LIWC): A computerized text analysis program. Mahwah, NJ: Erlbaum Publishers.

Pitts, V. (2004). Illness and Internet empowerment: Writing and reading breast cancer in cyberspace. health: An Interdisciplinary Journal for the Social Study of Health, Illness and Medicine, 8(1), 33-59.

Schegloff, E.A. (1997). Whose text? Whose context? Discourse and Society, 8(2), 165-87.

Scott, M. (1996). WordSmith. Oxford: Oxford University Press.

Scott, M. (1997). PC analysis of key words and key key words. System, 25(1), 1-13.

Seale, C.F. (2002). Cancer heroics: A study of news reports with particular reference to gender. Sociology, 36(1), 107-26.

Seale, C.F. (2005a). New directions for critical Internet health studies:

Representing cancer experience on the Web. Sociology of Health and Illness, 27(4), 515-40.

Seale, C.F. (2005b). Portrayals of treatment decision-making on popular breast and prostate cancer web sites. European Journal of Cancer Care, 14(2), 171-4.

Seale, C.F., Charteris-Black, J. and Ziebland, S. (2006). Gender, cancer experience and Internet use: A comparative keyword analysis of interviews and online cancer support groups. Social Science and Medicine, 62, 2577-90.

Speer, S. (2005). Gender talk: Feminism, discourse and conversation analysis. London: Routledge.

Spender, D. (1979). Language and sex differences. Osnabrücker Beitrage zür Sprachtheorie: Sprache und Geschlect, 11,38-59.

Stokoe, E. and Weatherall, A., Eds. (2002). Gender, language, conversation analysis and feminism. Discourse and Society, 13(6), 707-864.

Street, R.L. and Giles, H. (1982). Speech accommodation theory: A social cognitive approach to language and speech behavior. In M. Roloff and C.R. Berger (Eds.), Social cognition and communication, pp. 193-226. Beverly Hills, CA: Sage. 
health: 10(3)

Umberson, D. (1992). Gender, marital status and the social control of health behavior. Social Science and Medicine, 34(8), 907-17.

Wetherell, M. and Edley, N. (1999). Negotiating hegemonic masculinity: Imaginary positions and psycho-discursive practices. Feminism and Psychology, 9(3), 335-56.

\section{Author biography}

CLIVE SEALE's current research interests include the Internet, mass media and health, communication in health care settings and end-of-life care. Recent books include: Media and health (Sage 2003); Researching society and culture (Sage 2004); Social research methods: A reader (Routledge 2004); Qualitative research practice (edited for Sage 2004 with Silverman, Gubrium and Gobo). 